\title{
Benchmarking of the current solid waste management system in Karbala, Iraq using Wasteaware benchmark indicators
}

\author{
Muhammad Abdulredha \\ ${ }^{l}$ PhD student, Department of Civil Engineering, Liverpool John Moores University, UK. \\ Department of Civil Engineering, Kerbala University, Iraq. \\ E-mail address: m.a.abdulredha@2015.ljmu.ac.uk \\ Rafid AL khaddar
}

Head Department of Civil Engineering, Department of Civil Engineering, Liverpool John Moores University,

UK. E-mail address: $\underline{\text { r.m.alkhaddar@ljmu.ac.uk }}$

Patryk Kot

Department of Civil Engineering, Liverpool John Moores University, UK.

E-mail address: $\underline{\text { P.Kot@ljmu.ac.uk }}$

David Jordan

Natural Sciences and Psychology, Liverpool John Moores University, UK.

E-mail address: D.W.Jordan@ljmu.ac.uk

Ali Abdulridha

Department of Civil Engineering, University of Warith AL-Anbiya'a, Iraq.

E-mail address: Engali_alameri@yahoo.com

\begin{abstract}
Solid Waste Management (SWM) poses severe problems to the authorities of the city of Kerbala, one of the main tourism centres in Iraq. Due to the city's limited funds, it is crucial to evaluate the priorities for improvements in SWM services to tackle this problem efficiently. This paper employed Wasteaware benchmark indicators for integrated and sustainable solid waste management to evaluate the city SWM system performance. The data used in this evaluation was collected by in-depth interviews with the management authorities and field observations over two months in 2016. The outcomes showed that the SWM system in the city is weak. It therefore requires several improvements in physical infrastructure and management. Disposal and recycling were the highest priority to be improved among SWM physical components. While, in the management, the authority should have clear strategy for SWM and stakeholders such as public, private waste sector and informal waste collectors should be included in SWM planning to improve the management services. This study can provide a starting point for the city authorities to prioritise their actions to improve the current SWM system.
\end{abstract}

Keywords: Waste indicators, performance assessment, solid waste, integrated and sustainable waste management (ISWM), Kerbala.

\section{Introduction}

Municipal Solid Waste Management (MSWM) is a significant service that a city management authority delivers, as it highly influences the public health and the attractiveness of a city (Wilson et al., 2013b). 
Inappropriate Solid Waste Management (SWM) leads to serious impacts on the city environment, and economy prosperity; poorly managed Municipal Solid Waste (MSW) results in down-stream costs higher than the costs of the proper management of the waste in the first place (Wilson et al., 2015). In addition, a clean city is more attractive to visitors, big business and investors; the efficiency of a city's SWM system can be employed as an alternative indicator of good management authority who can be trusted with whom one can do business (Wilson et al., 2015). Proper standard indicators permit a city to review its own performance in terms of SWM services provision, support decision-makers to prioritise their actions for service improvement and monitor the changes in the SWM system over time (Wilson et al., 2013b). Moreover, consistent indicators, which simplify the comparison of the cities performance regardless their level of income, are suitable in various contexts such as increasing resource recovery and comparing different management tactics in many countries.

Performance indicators for SWM have been given a broad interest in literature. For instance, MacDonald (1996) studied bias concerns in the application of a set of indicators: MSW generation per capita; fraction of MSW being managed by several methods; and percentage of homes enjoying steady MSW collection service. Recently, researchers focused on developing indicators for certain features for updating a SWM system such as indicators for waste prevention (Wilts, 2012), for 3Rs (Reduce, Reuse, Recycle) strategies to shift from SWM to resource recovery (Hotta, 2014), and for zero MSWM systems (Zaman, 2014). Other researchers developed indicators to examine more aspects for instance tracing agreement with the European Union requirements (Cifrian et al., 2012) or to evaluate the performance of US cities (Greene and Tonjes, 2014). In addition, a set of benchmark indicators for Integrated Sustainable Waste Management (ISWM) was developed for SWM systems in many world cities, covering both physical components and governance aspects (Wilson et al., 2015). ISWM benchmark indicators, which was firstly developed in a work for UN-Habitat (Wilson et al., 2015), remain the most comprehensive in their coverage of SWM aspects; the only indicators that can be applied across a range of income levels; and wildly verified across many countries in deferent continents (Wilson et al., 2012). Benchmarking relays on acquiring truthful information about the state of SWM system in a particular city. However, there are many problems with such information including availability, accessibility and reliability (Wilson et al., 2015). Therefore, this information are considered as indicator for the quality of the SWM system particularly in low-income and middle-income countries (Wilson et al., 2012). Recently, SWM data were regularly recorded in the high-income countries. For instance, United Kingdom, in the early of 1990s, starts the publication of quarterly MSW data for local authority (Wilson et al., 2015).

Currently, SWM system applied in Kerbala, Iraq is in its preliminary stages (Abdulredha et al., 2017a). Several studies tried to document the issues of the system such as generation, composition and public participation (Abdulredha et al., 2017a, Abdulredha et al., 2017b, Al-masoudi and Al-haidary, 2015, Ali, 2009). However, there are very little if any previous studies analysed the current waste management 
system in Kerbala. Therefore, this study is devoted to evaluate the performance of the latter system using ISWM benchmark indicators and define its weakness and strength issues.

\section{Methodology}

\subsection{Analytical framework}

The concept of integrated and sustainable SWM known as ISWM (Scheinberg et al., 2010, Wilson et al., 2013b) is employed as analytical framework in this study. The latter framework differentiates three dimensions for evaluation of SWM System including physical system its components, sustainability aspects and stakeholders involvement. For analytical purposes, the ISWM framework has been divided in to two parts, the physical components and the governance aspects (Wilson et al., 2015), where stakeholders involvement was indirectly included in these two parts.

The physical components, the first part, concentrate on three key issues for development of SWM system (Wilson, 2007). The first issue, concentrating on keep up healthy conditions in a city and proper MSW collection service is the public health. Environmental protection, which is a second issue, is focusing on the protection of the city environment throughout the sequence of MSW treatment and disposal practises. The final issue is the resource recovery and management, which is the efforts exerted by the management authorities in the city to minimising the produced waste, recovering both materials and nutrients for beneficial use and materials recycling.

The second part, the governance's aspects of ISWM, focusing on the authority's strategies to provide a well organising and functioning SWM system, is divided in to three inter-related requirements. Firstly, inclusivity that provides transparent spaces for the stakeholders and allows them to contribute and benefit form SWM system as a service providers and users. Financial sustainability is the second requirement concerned with make sure that SWM services and practices are cost-effective and affordable to the public. The final requirement, sound institutions and pro-active policies, is concerned with the functionality of the SWM strategy and institutions for delivering proper waste management services.

Quantitative indicators were used for each component or aspect of ISWM benchmark inductors. For instance, the percentage SW collection coverage corresponding to the public health indicators, percentage of recycled MSW corresponding to the resources management (Wilson et al., 2013a), the percentage of total waste that goes to any sort of controlled disposal or treatment facility rather than uncontrolled dumping corresponding to environmental protection. A range of quantitative indicators related to the financial sustainability was used to cover MSW management budget effectiveness and affordability of the cost recovery mechanisms such as the percentage of the population that using and paying for MSW collection services (Scheinberg et al., 2010). Similarly, qualitative indicators for the governance aspects were used to evaluate the inclusivity, SWM sound institutions and policies. Each 
aspect was evaluated using several criteria that were assessed on a nominal scale (Scheinberg et al., 2010).

\subsection{Study area}

Kerbala city is one of the main tourism centres in Iraq, and is situated in the middle of the country, approximately 100 kilometre southwest of Bagdad, the capital (Abdulredha et al., 2017b)(see Figure 1). It has a total area of approximately5034 $\mathrm{Km}^{2}$ and population of $1,151,152$ capita according to the latest statistics provided by the Ministry of Planning of Iraq (ESD, 2014). The city has flat topography with elevation ranging between 30m-95m above the sea (Khalaf and Hassan, 2013).

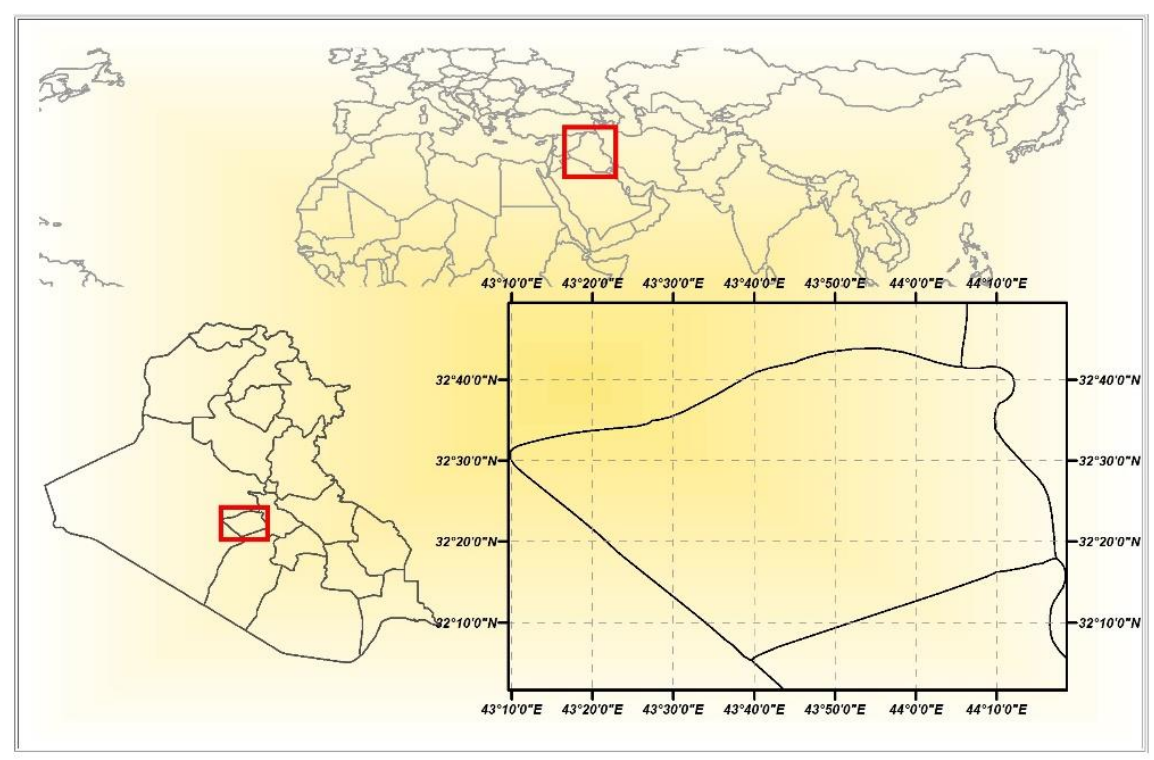

Figure 1: The geographical position of Kerbala city

Several mega festivals happen in the Kerbala, attracting millions of visitors from many courtiers around the world. According to Abdulredha et al. (2017a), in 2014, 18 million visitors went the city during one mega festival, generating an estimated 37,554 tonnes of waste. Unfortunately, MSW management system currently applied in the city is incompetent and not up to the challenge, as there are many illegal dumpsites and the collected waste are directly transported to the landfill site without treatment or materials recovery (Abdulredha et al., 2017b). Therefore, critical evaluation of the management system can address the challenges facing the city SWM system, which enables Kerbala authorities to prioritise their actions for SWM system improvements.

\subsection{Data collection and analysis}

The data used in this evaluation was drawn from a comprehensive study of published and unpublished government reports, in-depth interviews with waste management authorities in Kerbala city and on-site observations conducted over two months in 2016. The goal of interviews and field observation are to collect as much as possible of undocumented data regarding waste management system in the city such 
as key waste related data, waste collection services, waste treatment and disposal, financial aspects, and inclusivity of waste management providers and users.

Based on the goals of this study, a semi-structured interview schedule was developed in several stages guided by Bryman (2012) advice regarding the use of interview as a data collection method. After conducting comprehensive literature review on SWM aspects, the interview schedule items were formulated (Cifrian et al., 2012, Greene and Tonjes, 2014, MacDonald, 1996, Scheinberg et al., 2010, Wilson, 2007, Wilson et al., 2013a, Wilson et al., 2012, Wilts, 2012). Then, the schedule was revised and corrected according the suggestions of a panel of waste management and survey experts to meet a proper construct validity.

Purposive sampling was used in this study to reach the research goals (Bryman, 2012). The participants are officers in the SWM authorities who were in a position to give rich information regarding specific areas of interest. Nine participants were selected for this research.

The data collected in this study was analysed using thematic analysis (Bryman, 2012). QSR International NVivo 11, which is the most advanced analysis tool for qualitative research is used to analyse the data.

\section{Results and discussion}

\subsection{Participants' backgrounds and affiliations}

Nine senior officials from Kerbala SWM establishments were invited to take part in this study which was carried out from October to the end of November 2016. Participants were affiliated with three government organisations in charge of SWM in Kerbala including Kerbala Municipality (KM), Kerbala Municipalities (KMs) and Holy shrine authorities. All the participants were male with experience ranging from 4 to more than 10 years in the field of waste management.

\subsection{Background information and Key waste-related data}

MSW generation, composition and management varies according to the development of the city and the income level of its population. Therefore, a summary of background information and key wasterelated data as a complement to ISWM indicators is vital to interpret the indicators and provide proper judgement regarding the city status (Wilson et al., 2015). Table 1 shows summary of general background information of Kerbala city, Iraq. According to World Bank (2017), the Gross National Income (GNI) per capita for Iraq is $\$ 5,430$ which is corresponding upper-middle income level. The total municipal solid waste generation is around 650,000 tonne per year. MSW generation per capita per year and four components of MSW composition, which are important for the selection resource recovery methods, are shown in Table 1. According to Wilson et al. (2012), waste generation for uppermiddle income countries is ranging from $246 \mathrm{~kg} / \mathrm{capita} /$ year to $529 \mathrm{~kg} / \mathrm{capita} /$ year with an average of $373 \mathrm{~kg} / \mathrm{capita} /$ day. However, it can be clearly seen in Table 1 that the average SW generation in Kerbala 
of $547.5 \mathrm{~kg} / \mathrm{capita} /$ year is higher than the upper limit of MSW generation in upper-middle income countries. The increase of SW generation in Kerbala can be attributed to the huge number of tourists the gathered in the city during several mega festivals each year. MSW composition in Kerbala city is comparable to the composition in upper-middle income countries with higher fraction of organic and lower fraction of metal (Wilson et al., 2012).

Table 1: Kerbala City background information and key waste-related data

\begin{tabular}{|c|c|c|c|}
\hline No & Indicator & value & Justification or Source \\
\hline B1 & \multicolumn{2}{|c|}{ Income level } & \multirow{3}{*}{$\begin{array}{l}\text { Country data for } 2016 \text { from } \\
\text { http://data.worldbank.org/indicator/NY.GNP.PCAP.CD?locations=IQ }\end{array}$} \\
\hline 1 & GNI/capita & $\$ 5,430$ & \\
\hline 2 & Income level & Upper-middle & \\
\hline $\mathrm{B} 2$ & \multicolumn{2}{|c|}{ Population } & \multirow{4}{*}{$\begin{array}{l}\text { Environmental Statistics of Iraq for } 2014 \\
\text { http://www.mop.gov.iq/mop/index.jsp?sid=1\&id=243\&pid=1\&lng=en }\end{array}$} \\
\hline 1 & Total & $1,151,152$ & \\
\hline 2 & Urban & 773,506 & \\
\hline 3 & Rural & 377646 & \\
\hline B3 & $\begin{array}{c}\text { Total MSW } \\
\text { generation pert year }\end{array}$ & $650,000 \mathrm{t} / \mathrm{yr}$ & $\begin{array}{l}\text { This figure has been generated according the records of the municipal } \\
\text { solid waste management providers such as KM }\end{array}$ \\
\hline W1 & $\begin{array}{l}\text { SW generation per } \\
\text { capita } \mathrm{kg} / \mathrm{yr}\end{array}$ & $547.5 \mathrm{~kg} / \mathrm{yr}$ & According to the interview with the management authorities \\
\hline W2 & \multicolumn{3}{|r|}{ MSW composition for Kerbala city } \\
\hline W2.1 & Organic & 56.6 & \multirow{4}{*}{$\begin{array}{c}\text { According to study conducted by Al-masoudi and Al-haidary (2015) } \\
\text { analysing the composition of MSW generated from Kerbala city } \\
\text { residents according to the district. }\end{array}$} \\
\hline W2.2 & Paper & 12.3 & \\
\hline W2.3 & Plastic & 14.9 & \\
\hline W2.4 & Metal & 3.7 & \\
\hline
\end{tabular}

\subsection{Physical Components}

Data regarding the coverage of MSW collection and street cleaning in Kerbala city-the proportion of population accessing proper MSW collection system is showed as indicators 1.1 and 1.2 in Table 2 . Only $63 \%$ of the city population can access proper waste collection service. The city showed poor performance of MSW collection service coverage when it compared with the middle-income cities that have collection coverage in the range of 70-90\% (Wilson et al., 2012). MSW is collected either directly from households or from communal collection points by the city authorities, when it is transported in larger open or closed trucks to the disposal point. In addition, very high incidence of MSW accumulation around the collection points and illegal dumping has been observed (see Fig 2) 


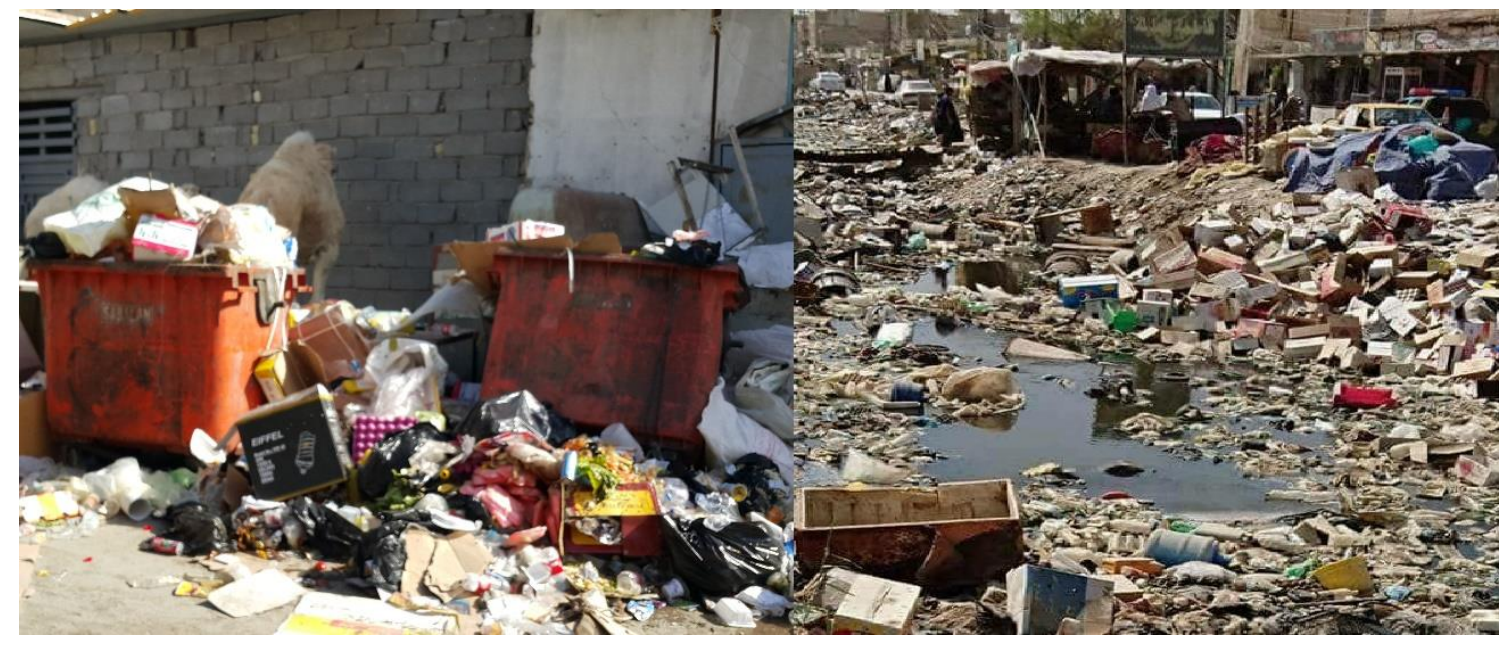

Figure 2: Solid waste accumulation around bins and illegal dumping

Indicator 2 in Table 2 illustrates the proportion of SW from the total waste collection system that is destined for controlled disposal. The dumpsite in Kerbala (see Fig. 3) is largely uncontrolled with no control over surface water, gases and periodic fire outbreak. In addition, the site lacks a gate control, fencing and waste placement which increases the potential of water, soil and air pollution. The controlled disposal is very low in Kerbala when it compared with middle-income countries of $95 \%$ controlled disposal (Wilson et al., 2012).

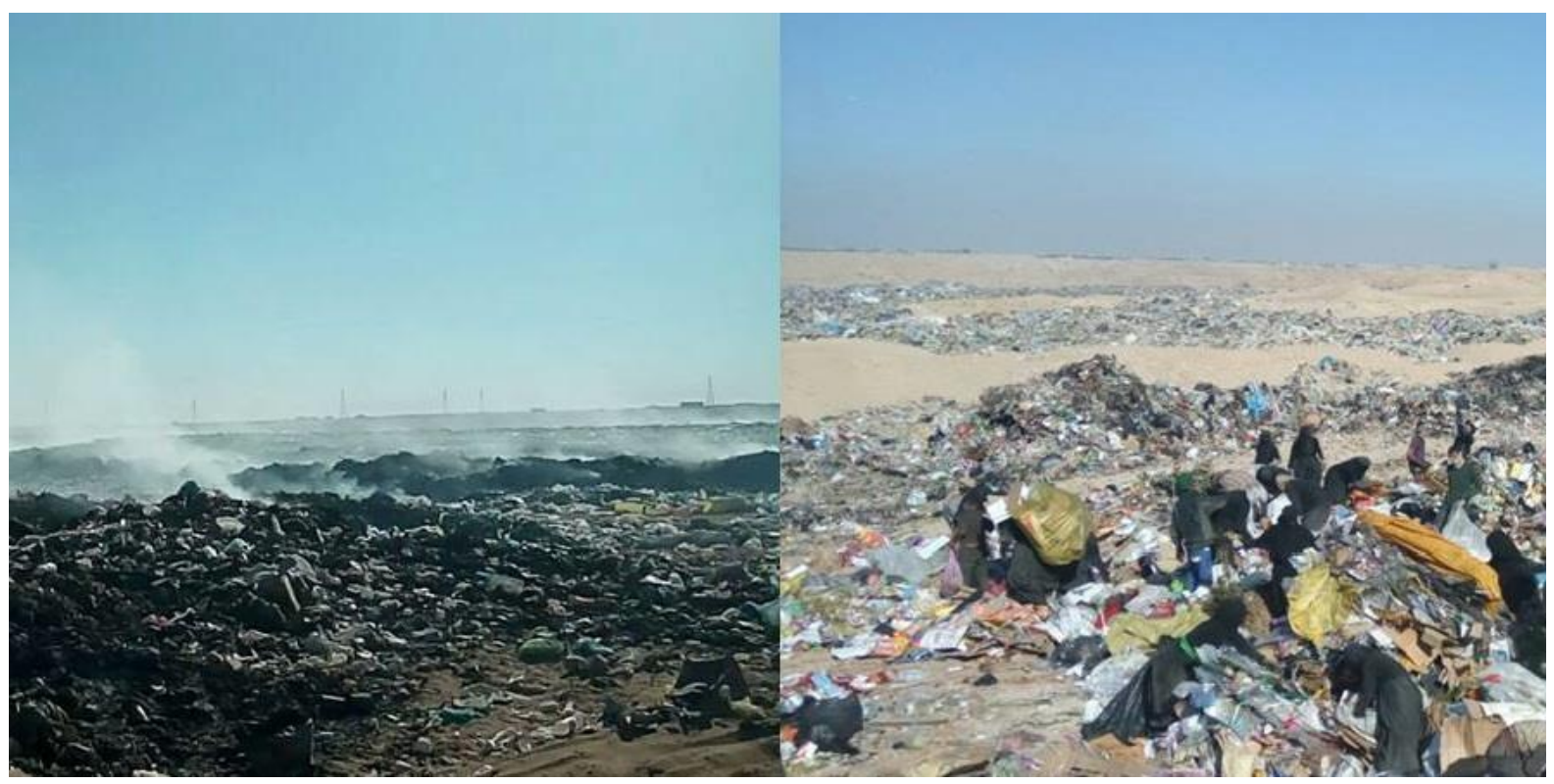

Figure 3: Control over the landfill site of the city of Kerbala

Indicator 3, Table 2, is the percentage of materials recovery through recycling and the use of organic waste in the agricultural application. Formal MSW recycling system is not exist in Kerbala, but it have active informal sector. According to the estimations of Kerbala authorities, less than $5 \%$ of MSW is 
recycled by informal sector. While, current recycling rates by the informal sector Bengaluru reported by Wilson et al. (2012) is $15 \%$.

Table 2: ISWM Benchmark indicators for physical components

\begin{tabular}{|c|c|c|c|}
\hline No & Category & Indicator & Results \\
\hline 1.1 & Public health - waste collection & Waste collection coverage & $63 \%(\mathrm{M} / \mathrm{H})$ \\
\cline { 1 - 3 } 1.2 & Waste captured by the system & N/A \\
\cline { 2 - 4 } 2 & $\begin{array}{c}\text { Environmental control- waste treatment and } \\
\text { disposal }\end{array}$ & $\begin{array}{c}\text { Controlled treatment and } \\
\text { disposal }\end{array}$ & $0 \%(\mathrm{~L})$ \\
\cline { 1 - 4 } 3 & $\begin{array}{c}\text { Resources management - Reduce, reuse and } \\
\text { recycling (3Rs) }\end{array}$ & Recycling rate & $<5 \%(\mathrm{~L})$ \\
\hline
\end{tabular}

Key: low performance (L) - red; low/medium performance (L/M) - red-orange; medium performance (M) - orange; medium-high performance $(\mathrm{M} / \mathrm{H})$ - orange-green; and high performance $(\mathrm{H})$ - green

\subsection{Governance aspects}

Indicators 4.1 and 4.2 of Table 3 present a qualitative evaluation of inclusivity for both users and providers of SWM services, based on a composite mark from a set of qualitative indicators. These indicators comprise several features such as equity of service provision, public involvement and feedback in decision-making on policy, public education and behaviour change, presence and representation of the private sector. Kerbala city showed very low score regarding user and provider inclusivity of $29 \%$ and $45 \%$ respectively. A proper system for public involvement in decision that directly affect them is weak or not exist. The city authorities have weak public education system with no observed behavioural change among citizens. In addition, most of SWM services delivered by the governmental sector and very low presence of private sector. According to Wilson et al. (2012), it is very important to work co-operatively with the informal sector and private sector, as they dramatically enhance the components of the management system and improve the financial aspect from MSW recycling.

Financial sustainability (indicator 5 in Table 3) is an indicator of proper SWM establishment (Wilson et al., 2012). Data regarding financial sustainability have been collected during this study such as budgets adequacy, source of financial allocations and cost recovery. The government cover most of the operating and maintenance costs of the current level of SWM services in Kerbala. In addition, a large proportion of Kerbala residents pay an affordable SWM service fee with water and wastewater utility bills. However, the cost recovered from the payment of the residents and some businesses is small when it compared with the total cost of waste management in Kerbala.

A robust institutional structure is important in SWM (Wilson et al., 2015). The degree of institutional coherence in Kerbala city has been evaluated using indicators 6.1 and 6.2 in Table 3. Weak authorities, lack of political commitment, weak central planning and weak co-operation among the city institutions have resulted in weak and unreliable waste management system. Despite several studies aimed to develop MSWM system in Kerbala, the city still has no engineered disposal site alternative to open dumpsite. Indicator 6 shows that the city has inadequate national framework and low institutional cooperation. 
Table 3: ISWM Benchmark indicators for governance aspects

\begin{tabular}{|c|c|c|c|}
\hline No & Category & Indicator & Results \\
\hline 4.1 & \multirow{2}{*}{ Degree of inclusivity } & User inclusivity & $29 \%(\mathrm{~L} / \mathrm{M})$ \\
\hline 4.2 & & Provider inclusivity & $45.0 \%(\mathrm{~L} / \mathrm{M})$ \\
\hline 5 & Degree of financial sustainability & Financial sustainability & $65 \%(\mathrm{M} / \mathrm{H})$ \\
\hline 6.1 & \multirow{2}{*}{$\begin{array}{c}\text { Sound institutions and proactive } \\
\text { policies }\end{array}$} & Adequacy of national SWM framework & $33.3 \%(\mathrm{~L} / \mathrm{M})$ \\
\hline 6.2 & & Local institutional coherence & $37.5 \%(\mathrm{~L} / \mathrm{M})$ \\
\hline
\end{tabular}

\section{Conclusions}

Indicators are commonly used tools to assess the performance of SWM systems and provide a basis for systems evaluations, ranking, comparisons and development processes. The current study is an evaluation of SWM system in Kerbala city, Iraq based on the wasteaware benchmark indicators for integrated sustainable waste management ISWM. The results indicate that the current waste management system in the city requires significant improvements in its physical components, particularly in terms of waste treatment, disposal and resources recovery (recycling). While, in governance aspects, the management authority should develop a clear strategy/policy that facilitate regional co-operation, improve the management services and introduce new technologies for waste treatment and disposal. In addition, further efforts are essential to include service users, informal sector and private sector in planning and decision-making. The identified key priority aspects are necessary for future planning and improvement of the present SWM system.

\section{Acknowledgment}

The current research is part of an on-going project analysing current solid waste management system in Kerbala particularly during mega festival conducted at Liverpool John Moores University with the support of the Higher Committee for Education Development in Iraq. The authors thank Karbala Center for Studies and Research, Kerbala municipality and the University of Kerbala for their assistance in data collection stage.

\section{References}

Abdulredha, M., Khaddar, R. a. L., Jordan, D. \& Alattabi, A. 2017a. Facing Up to Waste: How Can Hotel Managers in Kerbala, Iraq, Help the City Deal with its Waste Problem? Procedia Engineering, 196, 771-778.

Abdulredha, M., Khaddar, R. a. L., Jordan, D. \& Hashim, K. 2017b. The Development of a Waste Management System in Kerbala during Major Pilgrimage Events: Determination of Solid Waste Composition. Procedia Engineering, 196, 779-784.

Al-Masoudi, R. M. \& Al-Haidary, M. S. 2015. Spatial Analysis of Residential Waste Solid in the City of Karbala. Karbala University Journal, 13.

Ali, M. F. 2009. The study of solid waste collection to the city of Karbala. Journal of Engineering and Development, 12, 1-20.

Bryman, A. 2012. Social Research Methods, OUP Oxford.

Cifrian, E., Galan, B., Andres, A. \& Viguri, J. R. 2012. Material flow indicators and carbon footprint for MSW management systems: Analysis and application at regional level, Cantabria, Spain. Resources, Conservation and Recycling, 68, 54-66. 
Environment Statistics Department. 2014. Environmental Statistics of Iraq for 2014. Available: http://www.mop.gov.iq/mop/index.jsp?sid=1\&id=243\&pid=1\&lng=en 28/06/2016].

[Accessed

Greene, K. L. \& Tonjes, D. J. 2014. Quantitative assessments of municipal waste management systems: using different indicators to compare and rank programs in New York State. Waste Manag, 34, 825-36.

Hotta, Y. 2014. 3R Policy Indicator Factsheets-Discussion Paper [Online]. Asia Resource Circulation Policy Research Group. Kanagawa, Japan: Institute for Global Environmental Strategies (IGES).

Available: https://pub.iges.or.jp/system/files/publication_documents/pub/discussionpaper/3890/3RIndica tor_B5report_web.pdf [Accessed 22/09/2017].

Khalaf, R. M. \& Hassan, W. H. 2013. Evaluation of irrigation water quality index (iwqi) for al-dammam confined aquifer in the west and southwest of karbala city, iraq. International Journal of Civil Engineering (IJCE), 2, 21-34.

Macdonald, M. L. 1996. Bias Issues in the Utilization of Solid Waste Indicators. Journal of the American Planning Association, 62, 236-242.

London/Washington, DC: Earthscan for United Nations Human Settlements Programme [UNHABITAT]: http://thecitywasteproject. files. com/2013/03/solid_waste_management_in_the_worlds-cities. pdf (accessed 1 August 2015). 2010. Solid waste management in the world's cities. Water and Sanitation in the World's Cities 2010 (Vol. 50).

Wilson, D. C. 2007. Development drivers for waste management. Waste Management \& Research, 25, 198-207.

Wilson, D. C., Cowing, M. J., Mourdzhev, B., Gupta, S. K., Stretz, J. \& Schmidt, T. 2013a. Operator Models. Respecting Diversity: Annex 2-Benchmark Indicators, GIZ.

Wilson, D. C., Rodic, L., Cowing, M. J., Velis, C. A., Whiteman, A. D., Scheinberg, A., Vilches, R., Masterson, D., Stretz, J. \& Oelz, B. 2015. 'Wasteaware' benchmark indicators for integrated sustainable waste management in cities. Waste Manag, 35, 329-42.

Wilson, D. C., Rodic, L., Cowing, M. J., Whiteman, A., Stretz, J. \& Scheinberg, A. Benchmark Indicators for Integrated \& Sustainable Waste Management (ISWM). ISWA World Congress 2013 7-9 October 20132013 b Vienna

Wilson, D. C., Rodic, L., Scheinberg, A., Velis, C. A. \& Alabaster, G. 2012. Comparative analysis of solid waste management in 20 cities. Waste Management \& Research, 30, 237-254.

Wilts, H. 2012. National waste prevention programs: indicators on progress and barriers. Waste Manag Res, 30, 29-35.

World Bank. 2017. How we classify countries [Online]. Available: http:// data.worldbank.org/about/country-classifications [Accessed 13/05/2017].

Zaman, A. U. 2014. Measuring waste management performance using the 'Zero Waste Index': the case of Adelaide, Australia. Journal of Cleaner Production, 66, 407-419. 